\title{
College Students' Sports Life Style and Physical Education Teaching Reform in Colleges and Universities
}

\author{
Chaoqi $\mathrm{Fu}$ \\ Jiangxi Science and Technology Normal University, Nanchang, Jiangxi, \\ 330013
}

\begin{abstract}
However, the problem of students' physique and health is still very prominent. This is the core problem that plagued the work of school physical education. The school education thought must break through, and the education perspective must be transformed and strengthened. The reform of physical education in colleges and universities has been carried out for many years. Physical fitness and health are the fundamental of college physical education teaching. The formation of college students 'sports life style is the key to solve such problems. Therefore, the goal of college students' sports life style should be one of the important contents of university sports work. . In view of the main characteristics of the sports life style of college students, the development trend and related problems of school sports work, colleges and universities should strengthen research and implement reform in physical education teaching and strive to promote the formation and development of students' sports life style.

Keywords: Multi-objective bilevel programming, genetic algorithm, interpolation.
\end{abstract}

\section{Introduction}

College students' sports life style refers to the sum of the stable form and the behavior characteristic of the sports culture life formed by ordinary college students under the guidance of health first and lifelong sports thought in order to meet the multi-level needs in their learning process. The concept of sports life style of college students covers the ideological requirements of health first and 
lifelong sports, which also includes the multi-level needs of spiritual pleasure, personality display, cultural taste and health concepts, which embodies the awareness of college students' sports behavior characteristic. During the college period, there are plans to organize physical exercise and physical education of the way of life can not only make college students physical and health level can be enhanced and improved, but also help students form a healthy first and lifelong sports ideas, the sport as a Indispensable cultural life patterns in daily life behavior to establish a conscious and stable habit of physical exercise in order to effectively complete the purpose of health, which coincides with the idea of quality education for physical education requirements. It is the fundamental way to realize the health first and lifelong physical education, and it is the basic direction and important goal of the development of physical education, which can make the health education and physical education deep into the life of the students and make them play an effective role. The research on the present situation and promotion measures of college students' sports life style can reflect and evaluate the implementation of lifelong sports and health education in college physical education teaching more comprehensively and multi-levelly, and provide new ideas for the reform of college physical education teaching.

\section{The Relationship between the Teaching Reform of College Physical Education and the Cultivation of University Students' Sports Life Style}

Under the guidance of "health first" and "lifelong sports", college students' sports life style refers to the sum of stable form and behavior characteristic of sports culture life formed in order to meet the multi-level needs in the process of learning. . The concept of sports life style of university students covers the ideological requirements of "health first" and "life-long physical education", which also includes the multi-level needs of spiritual pleasure, personality display, cultural taste and health concept, Consciousness of Sports Behavior. During the university period, there are plans to organize physical exercise and sports life style not only can make college students physical and health level can be enhanced and improved, but also conducive to students to form a "healthy first" and "lifelong sports" ideas, the sports As an indispensable mode of cultural life, activities are established in the behavior of daily life to form a conscious and stable habit of physical exercise in order to effectively achieve the health purpose, which is in line with the "quality education" of the physical education requirements. It is not only the individual needs of students, the needs of society, but also meet the requirements of quality education, in line with the school physical education on the "health first" and "health first" and " Lifelong sports "guiding ideology, it is an important task of school physical education. It is the basic means to realize "health first" and "lifelong sports", and cultivate college students to form a healthy sports life style. It is also a good way to cultivate college students to form sports life style, which can make health education and 
physical education play an effective role in students' life. Is to enable students to effectively socialize the process of physical education is the development of the basic direction and an important goal. The research on the present situation and promotion measures of college students' sports life style can reflect and evaluate the implementation of "lifelong physical education" and "health education" in college physical education teaching more comprehensively and multi-levelly, and provide new teaching reform for college physical education.

Therefore, the college sports work reform should establish the basic direction for the life world, in order to cultivate students to form a healthy sports life style. The basic goal for the development of physical education is to enrich and perfect the idea of "lifelong physical education", to promote college students' sports life style The formation of the theoretical research should be a new vision of university physical education reform, focus, the core content and effective development approach. It is very important to give full play to the guiding role of $\mathrm{PE}$ teaching in colleges and universities, strengthen the teaching of physical fitness and physical fitness, and make full use of the various forms of school sports to carry out sports projects that can meet the needs of students' sports culture. At present, the strengthening of sports life on college students in sports sociology and health education theory, the establishment of college students physical exercise monitoring and evaluation system, developed for different groups of students the amount of scientific physical exercise guidelines, which scientific guidance of college sports Reform of education and teaching work has important practical significance.

\section{The Current Situation, Developing Trend and Related Educational and Teaching Problems of College Students' Sports Lifestyle}

It is bound to students from the sports life of the time, frequency (ie, the number of daily or weekly physical activity), projects, places, consumption and motivation to conduct a comprehensive examination. At present, college students participate in sports activities of sufficient time, high frequency, diverse activities, fixed places, economical and practical sports consumption, sport motivation diversity is the overall characteristics of college sports life [4,5]. In addition, there are the following trends in the way of college students' sports life: (1) In the field of consciousness, the pursuit of individual development, the pursuit of practicality, health concept has been strengthened. (2) The behavioral characteristics of sports life, college students sports life content showed a clear trend of modernization and expansion of sports life practice has gradually extended tendencies, sports consumption level continues to increase. (3) from the quality of life point of view, the quality of college students' sports life is constantly improving, college students sports life content, level, input and emotional experience effect has been greatly developed. (4) from the group characteristics, there is a clear trend of gender differentiation. 
At present, the lack of sports counseling after-school sports, practical facilities and equipment is relatively inadequate, college physical education teaching content and model development lags behind, making the existing campus sports and cultural life can not meet the growing needs of sports and cultural life of students. Therefore, in order to meet the needs of the development of sports life of modern college students to adopt a wide range of promotion model of the implementation of physical education, to accelerate the reform of teaching mode of physical education research, and expand the development of college sports cultural life, strengthen amateur sports cultural organization, Sports life counseling system, the rational development of the campus sports economy and the promotion of modern sports events, the expansion of activities equipment and strengthen the construction of practical venues and other aspects of the study is also very necessary.

\section{The formation of university students' sports life style and the reform of college physical education teaching}

The quality of physical education stage, this period to "enhance people's physique" as the guiding ideology, emphasizing the physical fitness of students "stronger, higher" education, followed by a "health first" thinking, embodies the physical education Humanistic thought, which is the school sports work in the guiding ideology of further comprehensive, emphasizing the "health first" is the school sports development ideological basis and work foundation. In fact, the physical fitness education is to be based on health education, to ensure health on the basis of the body to a higher and stronger content of education is scientific, if the lack of "health first" thinking foundation, "stronger, Higher "school physical education goals will be out of the question, the school sports can only be competitive. However, if physical education should be kept in a conservative state and lose the significance of "development", it is not the basic intention of health education on "health first", "health first" The connotation of the connotation of the comprehensive development of physical and mental health for the content, "development" is the purpose and direction, "health" and "development" is the school physical education teaching work inseparable two parts. But in the course of many years of practice, when the ideological foundation of "health first" should be emphasized, the tendency of physical education is denied, which deviates from the direction of the development of physical education and teaching, which makes the development of school sports work lost fundamental It is a prerequisite question of health education development that we can not ignore the relation between physical fitness education and "health first". The author believes that physical fitness education and health education should be an indispensable integral part of the whole process of physical education. Physical education teaching must be based on "healthy" and "healthy" First "as the ideological basis for physical fitness, 
physical education as the fundamental content and means, can enhance student health, to ensure the health of students.

College sports culture life should be the process of enriching students' whole study life. Its effective realization form and organization form should be omnidirectional and multi-level. The content should be rich and diversified, and should not be confined to the reform of PE classroom teaching And explore, after-school sports life should be as the main form of student sports cultural life is fully taken seriously. Therefore, deepening the organizational form of school sports reform, expand after-school sports organization form, establish and improve the after-school sports life counseling system should be mentioned on the agenda of the important up. Make full use of the organizational form of health education, strengthen the guidance of education and publicity, make full use of campus culture and easy organization, play sports associations, sports associations and sports club organization and management functions, organize a large number of colorful sports and cultural activities, Development of Sports Culture Life on Campus. The construction and management of campus culture should support the development of sports cultural life and the development of campus sports culture market, and try to create favorable external environment for the formation of university students' sports life style.

\section{Conclusion}

China's higher education model compared to the education model of developed countries, there are still many shortcomings, mainly biased in favor of the examination of the theory of education, ignoring the physical education and practice teaching, this teaching methods for students Growth and development of schools have increased negative impact, in order to improve the quality of life of college students in sports, in recent years, the major institutions have increased the reform of physical education and teaching, and constantly improve the physical education in college courses The proportion of the introduction of a variety of community to absorb the funds donated and the allocation of funds for education in the campus to establish a variety of college sports clubs and sports teaching facilities to improve the sports facilities in the per capita college students to meet the students of the To cultivate college students to form a good sports life style, in order to improve the physical quality of contemporary college students, to contribute to the promotion of social development of their own strength.

\section{References}

[1] Du Guoru. Study on the Physical Education System of Ordinary Colleges and Universities in China.Physiology, 2(3), pp. 12-13, 2004.

[2] Ma Lianpeng. The formation and promotion of scientific sports lifestyle . China Sport Science and Technology, 1(5), pp. 18-22, 2004. 
[3] Zhong Zhen-Xin, Yao Lei. Research on Physical Exercise Habits of College Students . Sports Science and Technology of China, 3(1), pp. 15-25, 2003.

[4] Pan Guobin. Survey and analysis of college students' sports humanistic consciousness . Journal of Sports Culture, 2(6), pp. 23-24, 2003.

[2] Song Yongping. The 21 st century Chinese social life style and sports . Journal of Sports Culture, 4(2), pp. 27-30, 2004. 